\title{
Differences between morphological characteristics and motoric capabilities of physically active and inactive female students
}

Rašidagić F. ${ }^{1 A B C D E}$, Nurković N. ${ }^{1 A C D E}$, Imamović - Turković Dž. ${ }^{1 A D E}$, Hadžibulić - Nurković H. ${ }^{2 \mathrm{CDE}}$, Nikšić E. ${ }^{3 \mathrm{ABDCE}}$, Kapo A. ${ }^{\text {BCD }}$

\author{
${ }^{1}$ Faculty of Sports and Physical Education, University of Sarajevo, Bosnia and Herzegovina \\ ${ }^{2}$ Faculty of Natural Sciences and Mathematics, University of Sarajevo, Bosnia and Herzegovina \\ ${ }^{3}$ Faculty of Education, University of Sarajevo, Bosnia and Herzegovina
}

Authors' Contribution: A - Study design; B - Data collection; C - Statistical analysis; D - Manuscript Preparation; E - Funds Collection.

\begin{abstract}
Purpose:

This research was done as continuation of research made previously on male population. The goal of this research is to determine "differences between morphological characteristics and motoric capabilities of physically active and inactive female students".

Material: $\quad$ Sample of physically inactive female students was made of 54 examinees and sample for active students was made of 52 girls. Average age was 12. All girls were primary school students. Physically inactive students regularly attended PE lessons and active students were involved in training process of basketball, volleyball, football and handball teams. Additional practice was done two times a week for 90 minutes. Morphological space is set by 15 variables and motoric space is set with 24 variables.

Results: $\quad$ Statistical difference was determined by T-test on level $(p<0.05)$. Significance given by T-test was checked by calculating Eta coefficient. Such data has differences in Chest Width $(.00 / .00$ and $\eta 2=0,33)$, Weight $(.00 / .00$ and $\eta 2=0,34)$, Stomach Skin Curves $(.00 / .00$ and $\eta 2=0,37)$ and Back Skin Curves $(.05 / .05$ and $\eta 2=0,16)$. Motoric space has differences in: Slalom with Three Medicine Balls $(.00 / .00$ and $\eta 2=0.01)$, Throwing medicine ball from the chest $(.00 / .00$ and $\eta 2=0,10)$, Long Jump $(.00 / .00$ and $\eta 2=0,17)$, Push-ups $(.02 / .02$ and $\eta 2=0.05)$, Sit-and-Reach $(.04 / .04$ and $\eta 2=0.00)$ and $20 \mathrm{~m}$ low start run $(.00 / .00$ and. $\eta 2=0,14)$.

Conclusions: $\quad$ After analysis it can be stated the aim of the research was completed and differences of anthropological status of physically active and inactive female students were determined. Students of age 12 can be recommended additional training activity to positively transform anthropological spaces with no transformation. Research with same or similar variables should be done on different age categories when compared to this one or to analyze quality of influence that specific sports have on transformation in this age category.

Keywords: $\quad$ primary school, additional sports activity, anthropological status, morphological characteristics and motoric capabilities.
\end{abstract}

\section{Introduction}

Research was done as continuation of already realized research with male population [1]. Given aim was to determine ,differences between morphological characteristics and motoric capabilities of physically active and inactive female students “. Just like male population with same age characteristics it is determined that sedentary way of life causes different diseases. Besides, child develops system of values and learns about some valuable characteristics, positive ways of behavior and communication, changes and shapes life habits by doing sports activities. Also, several researches have shown that doing sports positively decreases number of delinquency [2]. To prevent the disease to happen, it is necessary that children are active at least 60 minutes a day with medium to energic intensity [3,4]. Additional negative effect for health is also the fact that when students finish their education so do they stop with process of exercises [5]. Estimated 70\% of young people stops doing any kind of physical activity after they finish education. Data is confirmed by statistics done in USA where about 20 million children under the age of 14 does

\footnotetext{
(c) Rašidagić F., Nurković N., Imamović - Turković Dž., Hadžibulić -

Nurković H., Nikšić E., Kapo A., 2020

doi:10.15561/18189172.2020.0105
}

some kind of sport but three of four children give up those activities when they hit puberty or the age of 15 at the latest [6]. Such data shows strong negative influence of sedentary way of life so it is recommended that children choose their sports activities individually and what interests them so they will be highly motivated to practice $[7,8]$. According to some theoreticians, developing period of a 12-year-old is characterized by proportional emotional stability when compared to some other growing stages [9], so this life period should be properly used to promote and apply sports activities. Physically inactive female students have regularly attended PE lessons two times a week and those who were physically active had additional training activities outside of school also two times a week. Activities lasted for 90 minutes and selected sports were basketball, volleyball, handball and football. Since physically active students practice 4 times a week it is assumed their anthropological status is on higher development level than inactive students who practice 2 times a week $[10,11]$. For a student to be considered as athlete it is necessary to spend one year in training process. Students who participated in research are the same age so result of morphological and motoric transformation status can be a cause of ergogenic factors 
that is transformational processes which are result of sports clubs training [12]. Results of this research should determine higher level of morphological and motoric status development for physically active students and confirm increased movement activity which positively affects transformation of morphological characteristics and motoric capabilities. Research like this is important since it finds out different ways to increase movement activities of female students and decreases negative effects of sedentary way of life [13].

\section{Material and Methods}

\section{Participants}

Examinee sample are primary school girls from the area of Srednjebosanski Canton in Bosnia and Herzegovina. Average age is 12 years \pm 11 months. There were $\mathrm{N}=54$ of physically inactive female students. $\mathrm{N}=52$ is the number of physically active female students. According to Helsinki Measuring and Testing Propositions, student, parent and teacher permissions were given to do this tests. Only students who were completely healthy during the research could participate. Students could leave the research at any time.

\section{Research Desing}

Variables of morphological status are gathered in a way described by authors Šoše, \& Rađo [14] and measured: Body Height (VIST), Arm Length (DUZRUK), Leg Length (DUZNOG), Shoulders Width (SIRRAM), Pelvic Width (SIRKARL), Hand Width (SIRSAK), Foot Width (SIRSTOP), Middle Size of Chest (OBGRU), Size above knee (OBNTK), Size above elbow (OBNDL), Back Skin Curves (NBLED), Stomach Skin Curves (NBTRB), Above Elbow Curves (NBNDL), Above Knee Curves (NBNTK), Body Mass (MASTJ).

Variables of morphological status are gathered in a way described by authors Drljačić et al. [15] and Mikić [16] and measured: Bat Coordination (KOOPAL), Slalom with three medicine balls (SLA3MED), Low Eights (OSMSAG), Throwing medicine ball from laying position (BACMED), Long Jump (SKOKDAL), 20m running (TRC20M), Leg Tapping (TAPNOG), Leg Tapping against the Wall (TAPNOGZ), Hand Tapping (TAPRUK), Pushups on Loom (SKLEK), Sit-ups (LEZSJED), Deep Sit-ups with Pressure (CUCANJ), Standing on one leg on a bench with open eyes (OTVOCIUZ), Standing on one leg on a bench with closed eyes (ZATVOCIPOP), Standing on one leg on a balance bench with closed eyes (ZATVOCIUZ), Aiming with long stick (CILJDUGST), Leg pointing to vertical aim (CILJVERT), Hand pointing to horizontal aim (CILJHOR), Bat Turn (ISKRPAL), Laying on chest throw (ZANLEZGRU), Deep carry on bench (PRETKL), $20 \mathrm{~m}$ running from high start (TRCVISST), $20 \mathrm{~m}$ running from laying start (TRCLEZST), 20m running from flying start (TRCLETZST).

Statistical Analysis

Gathered data was analyzed in SPSS 22 program with license from Faculty of Sports and Physical Education, University of Sarajevo. Difference between groups was determined with T-test for independent samples on statistical significance level $\mathrm{P}<0.05$. Values above stated ones were not considered as statistically relevant. Significance of T-test up to 0.05 was checked by calculating eta coefficient about variant coverage between group results. Calculating of eta coefficient ( $\eta 2$ ) was done according to Cohen, [17] and Kolesarić, \& Tomašić-Humer, [18]: .01 - high coverage; .06 - medium coverage; .13 - small coverage of variant.

\section{Results}

Taking into consideration statistical indicators, one must state that results show only variables where there is clear descriptive statistical difference. Variables are additionally marked with number 1 of inactive students group whereas variable under number 2 (Table 1) are for active athletes group. Presented variables are normally distributed and suitable for further analysis. Table 1 shows that minimum and maximum group results have appropriate differences. Chest size in minimal $(62>58.2)$ and maximum $(86.1>79.2)$ result is higher on athletes while weight is lower (min. $30<31.2$ and $43.4<45.3$ ) which can indicate ,athletic body construction of this group ". Two measures of skin fat mass are also lower on athletes (NBTRB min. $1.0<2.0$ and NBTRB max. $9.0<15.0$, NBLED min. $1.0=1.0$ and NBLED max. $13.0<17.0$ ). When it comes to variables of motoric space, all variables presented by time component are „opposite "values and are lower in group of athletes which in this case is better result (SLA3MEDmin 20.5 $<22.5$, SLA3MEDmax 42.3<54.3, TRC20min 4.1<4.2, TRC20max $5.3<6.6$ ).

When morphological variables that had descriptive statistical difference were analyzed by T-test, four of them had differences. Those variables are: OBGK whose result relation in Standard Deviation are: 5.920/5.614 (Table 2) and do not exceed relation 1:1.5. Value Sig2 is .000/.000 with significant difference between results. Sig1 value .637 assumes difference between group results which confirms calculated eta coefficient .033. Variant coverage is small - results are different.

TEZ results in Standard Deviation (13.09/9.09) do not exceed relations 1:1.5. Values Sig2: .000/.000 indicate there is a difference between groups. Sig1 value .637 indicates that group results are not homogenous. After checking variant coverage of eta coefficient $\eta 2=.034$ it can be stated that there is a small variant coverage and big difference in weight measures

NBTRB in Standard Deviation (1.857/2.994) does not exceed relations 1:1:5 and shows homogenous results in groups and confirms normal distribution of results. Results Sig2 value: $.000 / .000$ indicate there is a difference between results. However, Sig1 value (.002) is somewhat higher than first two variables and is closer to limit of T-test significance. Checking results by calculating eta coefficient $(\eta 2=.037)$ makes us state low coverage of variants and one can confirm significance of T-test differences for this variable.

NBLED in Standard Deviation (2.696/3.836) exceeds relations 1:2. Data shows that measured group results are 
Table 1. Descriptive Statistics

\begin{tabular}{lllllll}
\hline Variables & N & Minimum & Maximum & Mean & Std. Deviation & $\begin{array}{l}\text { Std. Error } \\
\text { Mean }\end{array}$ \\
\hline OBGK1 & 54 & 58.2 & 79.2 & 68.66 & 5.614 & .778 \\
OBGK2 & 52 & 62.0 & 86.1 & 74.42 & 5.920 & .805 \\
TEZ1 & 54 & 31,2 & 45,3 & 38,25 & 9.09 & 2,49 \\
TEZ2 & 52 & 30.0 & 43,4 & 36,72 & 13.09 & 2.50 \\
NBTRB1 & 54 & 2.0 & 15.0 & 7.32 & 2.994 & .415 \\
NBTRB2 & 52 & 1.0 & 9.0 & 4.59 & 1.857 & .252 \\
NBLED1 & 54 & 1.0 & 17.0 & 5.64 & 3.836 & .532 \\
NBLED2 & 52 & 1.0 & 13.0 & 5.44 & 2.699 & .367 \\
SLA3MED1 & 54 & 22.5 & 54.3 & 33.15 & 6.381 & .884 \\
SLA3MED2 & 52 & 20.5 & 42.3 & 32.07 & 5.095 & .693 \\
BACMED1 & 54 & 175.0 & 320.0 & 219.17 & 38.241 & 5.204 \\
BACMED2 & 52 & 210.0 & 347.0 & 243.59 & 44.755 & 6.206 \\
SKOKD1 & 54 & 127.0 & 170.0 & 144.61 & 9.325 & 1.293 \\
SKOKD2 & 52 & 129.0 & 180.0 & 151.55 & 12.289 & 1.672 \\
SKLEK1 & 54 & 1.0 & 19.0 & 10.09 & 3.846 & 1.213 \\
SKLEK2 & 52 & 5.0 & 21.0 & 14.09 & 3.722 & 1.506 \\
LEZSJED1 & 54 & 10.0 & 28.0 & 20.51 & 3.468 & .4720 \\
LEZSJED2 & 52 & 14.0 & 31.0 & 22.63 & 3.597 & .4989 \\
TRC201 & 54 & 4.2 & 6.6 & 4.78 & .294 & .0401 \\
TRC202 & 52 & 4.1 & 5.3 & 4.96 & .336 & .0467 \\
\hline
\end{tabular}

Table 2. Morphological Characteristics, T-test for Independent Groups

\begin{tabular}{|c|c|c|c|c|c|c|c|c|c|c|}
\hline VAR & $\mathbf{F}$ & Sig 1 & $t$ & df & Sig 2 & $\begin{array}{l}\text { eta } \\
\text { n2 }\end{array}$ & Mean & $\begin{array}{l}\text { Std } \\
\text { Error }\end{array}$ & $\begin{array}{l}95 \% \\
\text { Low }\end{array}$ & Upp \\
\hline \multirow{2}{*}{ OBGK } & \multirow{2}{*}{.224} & \multirow{2}{*}{.637} & 5.131 & 104 & .000 & \multirow{2}{*}{0,33} & 5.754 & 1.121 & 1.387 & 3.925 \\
\hline & & & 5.136 & 103.97 & .000 & & 5.754 & 1.120 & 1.120 & 3.533 \\
\hline \multirow{2}{*}{ TEZ } & \multirow{2}{*}{.224} & \multirow{2}{*}{.637} & 5.216 & 104 & .000 & \multirow{2}{*}{0,34} & 5.874 & 1.226 & 1.136 & 10.34 \\
\hline & & & 5.147 & 101.77 & .000 & & 5.854 & 1.304 & .963 & 10.31 \\
\hline \multirow{2}{*}{ NBTRB } & \multirow{2}{*}{9.71} & \multirow{2}{*}{.002} & -5.67 & 104 & .000 & \multirow{2}{*}{0,37} & -2.736 & .482 & -3.692 & -1.780 \\
\hline & & & -5.62 & 84.595 & .000 & & -2.736 & .486 & -3.702 & -1.769 \\
\hline \multirow{2}{*}{ NBLED } & \multirow{2}{*}{3.774} & \multirow{2}{*}{.055} & .320 & 104 & .057 & \multirow{2}{*}{0,16} & .2058 & .642 & -1.068 & 1.479 \\
\hline & & & .318 & 91.261 & .051 & & .2257 & .646 & -1.078 & 1.490 \\
\hline
\end{tabular}

not homogenous. Values Sig2 .057/.051 indicate there is a significant difference between results. Sig1 value is .055 so one can assume that difference will be confirmed by T-test. Additional calculating of eta coefficient $\eta 2=$ ,16 confirmed border value about difference in variant coverage. However, it can be stated that present values go in favour of athlete female students for this variant.

T-test has shown that motoric capabilities have statistically significant difference in six variables: SLAL3MED that in Standard Deviation (Table 3) $5.095 / 6.381$ exceeds relation 1:3. Data shows higher difference in result variants and they are not homogenous. Values Sig2 .033/.033 in Table 3 show difference between groups and are confirmed after insight in Sig1 .174. Checking coverage of variant with eta $=0.01$ confirmed high coverage of results. Results between groups are not different.

BACMED in Standard Deviation is 38.241/44.755 and does not exceed values 1:1,5. Data shows low result coverage. Values Sig2 .003/.003 and Sig1 .986 show statistical significance of differences. By calculating eta coefficient $\eta 2=0.14$ border low result coverage between groups is confirmed so the result is better for athlete female students.

SKOKD in Standard Deviation is 12.289/9.325 and does not exceed values 1:1,5 so group results are confirmed. Values Sig2: .001/.001 and Sig1: .056 show statistically significant differences between group results. Calculating eta coefficient $\eta 2=.17$ confirms low results coverage which shows that SKOKD is better realized within athlete female students.

SKLEK in Standard Deviation is $(3.722 / 3.846)$ and 
Table 3. Motoric Capabilities, T-test for Independent Groups

\begin{tabular}{|c|c|c|c|c|c|c|c|c|c|c|}
\hline VAR & $\mathbf{F}$ & Sig 1 & $\mathbf{t}$ & df & Sig 2 & $\begin{array}{l}\text { eta } \\
\eta 2\end{array}$ & Mean & $\begin{array}{l}\text { Std } \\
\text { Error }\end{array}$ & $\begin{array}{l}95 \% \\
\text { Low }\end{array}$ & Upp \\
\hline \multirow{2}{*}{ SLA3MED } & \multirow{2}{*}{1.878} & \multirow{2}{*}{.174} & -.964 & 104 & .033 & \multirow{2}{*}{0.01} & -1.07 & 1.119 & -3.299 & 1.140 \\
\hline & & & -.960 & 97.48 & .033 & & -1.07 & 1.124 & -3.310 & 1.151 \\
\hline \multirow{2}{*}{ BACMED } & \multirow{2}{*}{.000} & \multirow{2}{*}{.986} & 3.024 & 104 & .003 & \multirow{2}{*}{0,14} & 24.41 & 8.075 & 8.405 & 40.43 \\
\hline & & & 3.015 & 100.24 & .003 & & 24.41 & 8.099 & 8.350 & 40.48 \\
\hline \multirow{2}{*}{ SKOKD } & \multirow{2}{*}{3.745} & \multirow{2}{*}{.056} & 3.326 & 104 & .001 & \multirow{2}{*}{0,17} & 7.066 & 2.125 & 2.852 & 11.28 \\
\hline & & & 3.343 & 98.66 & .001 & & 7.066 & 2.114 & 2.871 & 11.26 \\
\hline \multirow{2}{*}{ SKLEK } & \multirow{2}{*}{5.11} & \multirow{2}{*}{0.14} & 2.32 & 104 & .021 & \multirow{2}{*}{0.05} & 4.99 & 2.32 & .5386 & 5.45 \\
\hline & & & 1.10 & 91.12 & .022 & & 4.31 & 2.12 & .5366 & 5.45 \\
\hline \multirow{2}{*}{ LEZSJED } & \multirow{2}{*}{.012} & \multirow{2}{*}{.911} & -.169 & 104 & .048 & \multirow{2}{*}{0.00} & -.1161 & .6863 & -1.47 & 1.24 \\
\hline & & & -.163 & 103.423 & .046 & & -.1341 & .6525 & -1.47 & 1.24 \\
\hline \multirow{2}{*}{ TRC20 } & \multirow{2}{*}{.110} & \multirow{2}{*}{.741} & -2.93 & 104 & .004 & \multirow{2}{*}{0,14} & -.1801 & .0614 & -.301 & -.058 \\
\hline & & & -2.92 & 101.04 & .004 & & -.1925 & .0615 & -.302 & -.058 \\
\hline
\end{tabular}

does not exceed relations 1:1,5. Data shows group results in both samples. Sig2 .021/.021 and Sig1 0.14 show significant difference between groups and low coverage of variant. Additional checking of $\eta 2=0.05$ confirmed medium to high result coverage and it can be stated they are not significantly different.

LEZSJED in Standard Deviation is $(3.468 / 3.597)$ and has concentrated result relation in groups $(1: 1,5)$. Value Sig2 .048/.046 shows statistical difference between groups. Sig1 value is .911 and eta coefficient is $\eta 2=0.00$ which shows high result coverage and confirms small significance of differences given by T-test.

TRC20 in Standard Deviation (.294/.336) has values $1: 1,5$ that is there are group results within groups. Values (Table 4.) Sig2 .004/.004 show there is difference between results. Sig1 value is.741 so it is assumed that T-test is not so statistically significant and there is result coverage. This is confirmed by calculating eta coefficient $\eta 2=0.14$ which shows small difference between results.

\section{Discussion}

Numerous researches have established that additional movement activity affects more developed anthropological status [19, 20, 1, 21]. Second important factor is cognitive readiness and child's capability to understand reasons why sport is important which is a characteristic of a 12-year-old population [22]. Because of that, determining influences of additional movement activity on anthropological status transformation of primary school female students is organized and this research was done.

Difference between anthropological statuses was checked for morphological characteristics and motoric capabilities. Even though large number of morphological variables was examined -15 to be exact, after final T-test determination and calculation of eta coefficient, this research presented only four of them. Given procedure was done since there was a difference shown by T-test and additionally checked by calculating eta coefficient for each of above mentioned variables. Only variables with low result coverage and high eta coefficient $(\eta 2)$ were accepted as significantly different. Such criteria were insisted upon because values of T-test have been set on border level $(\mathrm{p}<0.05)$.

Morphological characteristics checked by T-test have shown differences in: Chest Size (OBGK), Weight (TEZ), Stomach Skin Curves (NBTRB) and Back Skin Curves (NBLED). Everything indicates that additional sports activity realized through training process of games has influence on lower body weight and less skin fat tissue on female athletes (Witt and co. 2005). This data is not so important for back skin curves which is surprising since other variables should be significantly lower on female athletes. Given result is not in accordance with research results done by [23, 24, 25].

Same work methods were applied on motoric capabilities as well as morphological characteristics when it comes to result representation in this research. T-test has shown significant development in six variables: SLA3MED, BACMED, SKOKD, SKLEK, LEZSJED and TRC20. To check significant difference given by T-test, variant coverage for each of these variables was done. Variables with low result coverage have been accepted as significantly different. It can be stated that three variables had low result coverage that is eta coefficient was calculated ( $\eta 2)$. Throwing medicine ball from chest (BACMED), Long jump (SKOKD) and $20 \mathrm{~m}$ running from low start (TRC20) are better developed on athlete female students. The rest of the variables in motoric space do not show statistically significant difference. Given results are in accordance with research done by $[26,27]$ as well as research by authors Đukić, et al. [28] and Vrbik, et al. [29]. Thanks to additional sports activity of two times a week per 90 minutes, female active athletes have had certain transformation of motoric and morphological status. However, it can be stated because of calculated eta coefficients that there was bigger transformation on morphological characteristics [30, 31]. Also, one can claim that research aim was completed and ,differences 
between morphological characteristics and motoric capabilities of physically active and inactive female students" were determined. Weakness of this research can be seen in the absence of insight into adjustment of training activities to age group of examinees in this research. Students should give additional data about their nutrition and free time movement. Research could be organized and done on different age or sex categories and all given data would give additional knowledge about existence of determined differences.

\section{Conclusion}

Thanks to additional sports activity of two times a week per 90 minutes, female active athletes have had certain transformation of motoric and morphological status. However, it can be stated because of calculated eta coefficients that there was bigger transformation on morphological characteristics Also, one can claim that research aim was completed and „differences between morphological characteristics and motoric capabilities of physically active and inactive female students" were determined. Weakness of this research can be seen in the absence of insight into adjustment of training activities to age group of examinees in this research. Students should give additional data about their nutrition and free time movement. Research could be organized and done on different age or sex categories and all given data would give additional knowledge about existence of determined differences.

\section{Funding}

This research received no external funding.

\section{Conflicts of Interest}

The authors declare no conflict of interest.

\section{References}

1. Rašidagić F, Imamović Dž. Differences Between Morphological and Motoric Status of Female Students in Central and Peripheral City Areas. Sport Science. 2018;11(1): $119-123$.

2. Barnett NP, Smoll FL, Smith R. Effects on Enhancing Coachathlete Relationship on Youth Sport Attrition. The Sport Psychologist. 1992; 6: 111-127.

3. Centers for Disease Control and Prevention. Youth Risk Behavior Surveillance. MMWR United States. 2010; 59 (SS-5); 1-127. https://doi.org/10.1123/tsp.6.2.111

4. US Department of Health and Human Services. Strategies to improve the quality of physical education. [Internet]. 2010 [updated 2019 Feb 10; cited 2019 Sep10]. Available from: Washington: https://www.cdc.gov/healthyschools/pecat/ quality_pe.pdf

5. Donovan M, Jones G, Hardman K. Physical Education and Sports. Kinesiology. 2006; 38(1): 16-27.

6. Papalia DE, Olds SW, Feldman RD. A child's world: Infancy through adolescence. The McGrow Hill Companies. Inc. New York, USA, 1999.

7. Šiljković Ž, Rajić V, Bertić D. Extra-curricular and Activities Outside of School. Educational Science. 2007;9(2): 113-145.

8. Martinčević J. Free Time and Students' Involvement in Extra-curricular Activities Outside of School. Life and School. 2010; 24(56): 19-34.

9. Horga S. Children in Sport and Physical Activity: Match or Mismatch of Needs and Demands. In: Pišot R, Štemberger $\mathrm{V}$, ed. A child in Motion Proceedings, Ljubljana: Univerza V Ljubljani; 2000. P.24-38.

10.Hills AP, King NA, Armstrong TP. The Contribution of Physical Activity and Sedentary Behaviors to the Growth and Development of Children and Adolescents. Sports Med. 2007; 37(6): 533 - 545. https://doi.org/10.2165/00007256-200737060-00006

11.Physical Activity Guidelines Advisory Committee. Physical activity guidelines advisory committee report. Washington, DC: US Department of Health and Human Services; 2008. A1-H14.

12.Batričević D. Discriminatory Analysis of Motoric and Functional Capabilities on Athlete and Non - Athlete Students. Sport Science. 2008; 1: 50-53.

13.Jamner M, Spruijt-Metz D, Bassin S, Cooper D. A Controlled
Evaluation of a School-based Intervention to Promote Physical Activity Among Sedentary Adolescent Females: Project FAB. Journal of Adolescent Health. 2000; 34: 279- 289. https://doi.org/10.1016/S1054-139X(03)00272-6

14.Šoše H, Rađo I. Kinesiology Measurements. Faculty of Physical Education. Sarajevo; 1998.

15.Drljacic D, Arsic K, Arsic D. Eurofit test battery for the assessment of physical abilities and health fitness in children. PONS - Medicinski Casopis, 2012;9:158-64. (In Bosnian) https://doi.org/10.5937/pons1204158D

16.Mikić B. Sports Testing and Measuring. Faculty of Philosophy, University of Tuzla; 1999.

17.Cohen J. Statistical Power Analysis for the Behavioral Sciences. Hillsdale, NJ: LEA; 1988.

18.Kolesarić V, Tomašić-Humer J. Greatness of Impact. Faculty of Philosophy. University of Josip Jurja Strossmayer. Osijek; 2016.

19.Blašković M, Matković B, Matković B. Influence of Physical Activity on Development of Some Basic Motoric Capabilities on Boys. Kineziology. 1993; 25(1-2): $33-38$.

20.Kondrić M, Mišigoj-Duraković M, Metikoš D. Contribution to knowledge of the relation of morphological and motor features 7-19-year students. Kinesiology, 2002; 34(1), 5-14.

21.Bavčević T, Vlahović L, Božinović-Mađor S. Structure of Morphological Space on 6-year-old and 7-year-old Students. 15th Summer School of Kineziologists in Republic of Croatia. 2017. P. 67-72.

22.Brustad RJ, Babkes ML, Smith AL. Youth in sport: Psychological considerations. Handbook of sport psychology, 2001; 2, 604-635.

23.Kapo S, Čaušević D, Doder I, Kapo A, Gurda E, Kapo N, Čuljević A, Fočo R, Bandić M, Čović N. Effects of Physical Education Classes On Body Composition and Muscular Fitness in Primary School Children. Acta Kinesiologica. 2018;12(2): 51-56.

24.Prahović M, Protić J. Differences in Anthropological Characteristics Between 14-year-old Players of Football, Basketball and Handball and Non - Athletes. In: Vladimir Findak, ed. Anthropological, Methodical, Methodological, Professional Assumptions of Work in the Fields of Sport, Sport Recreation and Kineziotherapy. Zagreb: Croatian Association of Kinesiology, 2007; 16. P. 470-476.

25.Kruschitz R, Wallner-Liebmann SJ, Hamlin MJ, Moser M, Ludvik B, Schnedl WJ, Tafeit E. Detecting body fat-a 
weighty problem BMI versus subcutaneous fat patterns in athletes and non-athletes. PLoS One, 2013; 8(8), e72002. https://doi.org/10.1371/journal.pone.0072002

26.Čoh M. Methodology and Diagnosis of Jump Development in Conditional Training of Athletes. Summary of International Science Summit. Conditional Training of Athletes. Faculty of Kinesiology, University of Zagreb and Association of Conditional Trainers in Croatia; 2004. P.104-118.

27.Bajrić O, Bašinac I, Srdić V, Bajrić S. Factorial Structure of Morphological and Motoric Space on Athlete and NonAthlete Students. Summary of Works - Proceedings, Sixth International Conference "Sports Science and Health". Pan European University, Banja Luka; 2016. P. 132 - 141.

28.Đukić B, Kalentić T, Vujkov N, Vujanović S, Smajić M. Differences in Explosive Strength of Legs and Speed of Separate Movements of Tennis and Table Tennis Players.
Biberović A, ed. Summary of Works „7th International Symposium, Sports and Health". Tuzla: Faculty of Sports and Physical Education, University of Tuzla; 2014. P. 76-79.

29.Vrbik I, Čižmek A, Peršun J. Funkcionalne sposobnosti učenika u osnovnoj školi [Functional abilities of elementary school students]. Zbornik radova Tjelesna $i$ zdravstvena kultura, 2011;21: 512-519. (In Croatian)

30.Bojić A, Šljivić E, Dedić V, Bojić S, Dautović A. Differences in Skeleton Dimensions and Motoric Capabilities of Students in Rural and Urban Areas in Tuzla Canton. Sixth International Conference "Sports Science and Health ", 2016; 1:21 - 28.

31.Gojković G. Effects of Physical Education on the Morphological Characteristics and Postural Status of Children. Courier of Serbia's Anthropological Society, 2009; 44:171-177.

\section{Information about the authors:}

Rašidagić F.; http://orcid.org/0000-0002-1153-5719; faris.rasidagic@gmail.com; Faculty of Physical Education and Sport, University of Sarajevo; 71000 Sarajevo, Bosnia and Herzegovina.

Nurković N.; http://orcid.org/0000-0002-8705-4217; n.nurkovic@gmail.com; Faculty of Physical Education and Sport, University of Sarajevo; 71000 Sarajevo, Bosnia and Herzegovina.

Imamović-Turković DŽ.; http://orcid.org/0000-0001-8348-8053; imamovicdzenana@gmail.com; Faculty of Physical Education and Sport, University of Sarajevo; 71000 Sarajevo, Bosnia and Herzegovina.

Hadžibulić-Nurković H.; http://orcid.org/0000-0001-8098-9880; 1512hana@gmail.com; Faculty of Natural Sciences and Mathematics, University of Sarajevo; 71000 Sarajevo, Bosnia and Herzegovina.

Nikšić E.; (Corresponding author); http://orcid.org/0000-0002-1849-9693; elvira.beganovic1982@gmail.com; Faculty of Education Science, University of Sarajevo; 71000 Sarajevo, Bosnia and Herzegovina.

Kapo A.; http://orcid.org/0000-0002-7865-806X; anida.kapo2@gmail.com; Faculty of Education Science, University of Sarajevo; 71000 Sarajevo, Bosnia and Herzegovina.

Cite this article as:

Rašidagić F, Nurković N, Imamović - Turković Dž, Hadžibulić - Nurković H, Nikšić E, Kapo A. Differences between morphological characteristics and motoric capabilities of physically active and inactive female students. Pedagogy of physical culture and sports, 2020;24(1):30-35. https://doi.org/10.15561/18189172.2020.0105

This is an Open Access article distributed under the terms of the Creative Commons Attribution License, which permits unrestricted use, distribution, and reproduction in any medium, provided the original work is properly cited (http://creativecommons.org/licenses/by/4.0/deed.en).

Received: 02.10 .2019

Accepted: 25.10.2019; Published: 10.11.2019 